Research Article

\title{
Head-To-Head Comparison of Treatment Failure and Costs among COPD Patients Who Used Noninvasive Ventilation in the Ward versus in the ICU: A Propensity-Matched Cohort Study
}

\author{
Yueling Hong, ${ }^{1}$ Qiao Liu, ${ }^{1}$ Linfu Bai, ${ }^{1}$ Lei Jiang, ${ }^{1}$ Xiaoli Han, ${ }^{1}$ Shicong Huang, \\ Wenhui Hu, ${ }^{1}$ Jun Duan ${ }^{1}{ }^{1}{ }^{1}$ and Chuanbo Liu $\mathbb{D}^{2}$ \\ ${ }^{1}$ Department of Respiratory and Critical Care Medicine, The First Affiliated Hospital of Chongqing Medical University, \\ Chongqing 400016, China \\ ${ }^{2}$ Department of Critical Care Medicine, The People's Hospital of Gaoxin District, Chongqing 400039, China
}

Correspondence should be addressed to Jun Duan; duanjun412589@163.com and Chuanbo Liu; 37445615@qq.com

Received 10 November 2020; Revised 14 December 2020; Accepted 18 December 2020; Published 31 December 2020

Academic Editor: Andrea S. Melani

Copyright (C) 2020 Yueling Hong et al. This is an open access article distributed under the Creative Commons Attribution License, which permits unrestricted use, distribution, and reproduction in any medium, provided the original work is properly cited.

\begin{abstract}
Background. Head-to-head comparison of treatment failure and costs among chronic obstruct pulmonary disease (COPD) patients who used noninvasive ventilation (NIV) in the ward versus in the ICU is lacking. Methods. This retrospective study was performed in a department of respiratory and critical care medicine in a teaching hospital. COPD patients who used NIV in the respiratory ward or respiratory ICU were screened. We enrolled patients with $\mathrm{PaCO}_{2}$ more than $45 \mathrm{mmHg}$ and $\mathrm{pH}$ less than 7.35 before the use of NIV. Results. We enrolled 83 patients who initiated NIV in the ward and 319 patients in the ICU. Only 5 (6\%) patients in the ward were required to transfer to ICU for intensive care. The vital signs were worse but improved faster within $24 \mathrm{~h}$ of NIV among patients in the ICU than those in the ward. The NIV failure, hospital mortality, and the length of stay in hospital did not differ between the two groups. However, the duration of NIV was shorter (median 4.0 vs. 6.1 days, $p<0.01$ ) and hospital costs were higher (median 4638 vs. 3093 \$USD, $p<0.01$ ) among patients in the ICU than those in the ward. After propensity matching, 42 patients were left in each group, and the baseline data were comparable between the two groups. The findings in the overall cohort were confirmed again in the propensity-matched cohort. Conclusions. Among COPD patients, the use of NIV in the ward leads to longer duration of NIV, but lower hospital costs, and similar NIV failure and mortality compared with those in the ICU.
\end{abstract}

\section{Introduction}

The prevalence of chronic obstructive pulmonary disease (COPD) is $8.6 \%$ in adult population and $13.7 \%$ in those aged 40 years or older [1]. It leads to high morbidity and mortality and becomes the third leading cause of death in China $[2,3]$. Also, the cost burden in COPD patients is much higher than non-COPD subjects [4]. At the end stage, shortness of breath and hypercapnia are the main clinical features in COPD patients. Therefore, relief of dyspnea and reduction of $\mathrm{PaCO}_{2}$ are two main therapeutic regimens.

In COPD patients, noninvasive ventilation (NIV) improves minute ventilation and decreases the work of breathing [5]. NIV also reduces the need of intubation and mortality in this population [6,7]. Guidelines have strongly recommended the use of NIV in hospitalized patients due to COPD exacerbations [8-10]. Also, the use of NIV in hospitalized COPD patients is increasing year by year [11].

Among COPD patients, the use of NIV in the intensive care unit (ICU) is common [12-14]. As ICU beds are limited, not all COPD patients can admit to ICU for application of NIV. The ward is another place where the NIV can be used. Several studies have reported that use of NIV in the ward is feasible [15-17]. However, head-to-head comparison of treatment failure and costs among COPD patients who used noninvasive ventilation (NIV) in the ward versus in the ICU is lacking. Here, we aimed to explore the optimal location to use of NIV in COPD patients. 


\section{Methods}

This was a retrospective observational study performed in a teaching hospital from March, 2015, to June, 2018. We screened all the patients who used NIV as first-line therapy due to COPD exacerbation in the respiratory ward or respiratory ICU and enrolled the patients with $\mathrm{pH}$ less than 7.35 and $\mathrm{PaCO}_{2}$ more than $45 \mathrm{mmHg}$. However, the patients with refusal of intubation were excluded. The diagnosis of COPD was based on the criteria published by Chinese Medical Association [18]. The study protocol was approved by our ethics committee (the First Affiliated Hospital of Chongqing Medical University). As this was a retrospective study, the informed consent was waived.

In the respiratory ward, the bed nurse ratio was $1: 0.4$ and the bed physician ratio was $1: 0.5$. In the respiratory ICU, the bed nurse ratio was $1: 2.5$ and the bed physician ratio was $1: 0.6$. Use of NIV in the ward or in the ICU was decided by the attending physicians based on the volume of ICU beds, ability to pay, and patients' wishes. In our hospital, the indications of NIV in patients with COPD exacerbation were as follows: (1) respiratory rate more than 25 breaths/min, (2) $\mathrm{PaCO}_{2}$ more than $45 \mathrm{mmHg}$, (3) $\mathrm{pH}$ less than 7.35, (4) $\mathrm{PaO}_{2} / \mathrm{FiO}_{2}$ less than $200 \mathrm{mmHg}$, and (5) vigorous activity of accessory respiratory muscles [19].

The pneumologist took care of the NIV patients in the ward. When the NIV has been used for more than 2 hours, the patients in the ward were considered to be transferred to ICU for escalation therapy if the respiratory failure got worse. The criteria were respiratory rate more than 35 breaths/min, $\mathrm{pH}$ less than 7.25, $\mathrm{PaO}_{2} / \mathrm{FiO}_{2}$ less than $100 \mathrm{mmHg}$, unstable hemodynamic status, and other causes required intensive care. However, this was decided by the attending physician's discretion.

The management of NIV (BiPAP Vision or V60; Philips Respironics, Carlsbad, CA) in COPD patients was based on our hospital protocol [19-21]. The face mask was the first choice for the interface to connect the ventilator to the patient. The size of the face mask was fitted to the face type. Bilevel positive airway pressure was used for all patients. The expiratory positive airway pressure was initially set at $4 \mathrm{~cm}$ $\mathrm{H}_{2} \mathrm{O}$, and it was titrated to diminish the ineffective trigger. Usually, the expiratory positive pressure ventilation was maintained at 4 to $8 \mathrm{~cm} \mathrm{H}_{2} \mathrm{O}$. The inspiratory positive airway pressure was initially set at $8 \mathrm{~cm} \mathrm{H}_{2} \mathrm{O}$ and then gradually increased to achieve the best control of dyspnea or to the tolerance of the patient. Usually, the inspiratory positive airway pressure was maintained at 15 to $20 \mathrm{~cm} \mathrm{H}_{2} \mathrm{O}$ within 30 minutes. The fractional concentration of inspiratory oxygen $\left(\mathrm{FiO}_{2}\right)$ was adjusted to maintain the bedside $\mathrm{SpO}_{2}$ above $90 \%$ and the $\mathrm{PaO}_{2}$ above $60 \mathrm{mmHg}$. At the initial phase, continuous use of NIV was encouraged except drinking, eating, and sputum excretion. If the respiratory failure relieved, intermittent use of NIV was performed until the NIV was weaned. However, in those whose respiratory failure progressively deteriorated and required invasive mechanical ventilation, intubation was performed. The NIV failure was defined as requirement of intubation or death during NIV intervention. In addition, the decision to transfer the patient to ICU for escalation therapy was based on the attending physicians' discretion if the respiratory failure progressively deteriorated.

We collected the age, gender, underlying disease, vital signs, and arterial blood gas tests. The disease severity was assessed by the acute physiology and chronic health evaluation II (APACHE II) score. The prognostic outcomes were also collected including the rate of NIV failure and hospital mortality. The resource consumption was assessed including the duration of NIV, length of stay in hospital, and hospital cost. All the data we collected were extracted from the medical records.

2.1. Statistical Analysis. The continuous variable was reported as mean value and standard deviation or median value and interquartile range (IQR) when appropriate. Differences between two groups were analyzed with the use of Student's $t$-test or the Mann-Whitney $U$ test. Categorical variable was reported as numbers and percentages, and the differences between groups were analyzed with the use of Chi-square or Fisher's exact tests. $p$ values less than 0.05 were considered statistically significant.

Propensity scores were estimated using multiple logistic regression analyses, with adjustments for age, gender, underlying disease, APACHE II score, GCS, respiratory rate, heart rate, mean arterial pressure, $\mathrm{pH}, \mathrm{PaCO}_{2}$, and $\mathrm{PaO}_{2}$ / $\mathrm{FiO}_{2}$. After calculating propensity scores, we matched the patients who initiated the NIV in the ward and those in the ICU with similar propensity scores at a $1: 1$ ratio, using the nearest neighbor method, no replacement, and a 0.05 caliper width.

\section{Results}

In the overall cohort, 83 patients initiated NIV as first-line therapy in the ward and 319 patients in the ICU (Table 1). Compared with the subjects in the ICU, the patients who initiated the NIV in the ward had lower respiratory rate ( $24 \pm 3$ vs. $28 \pm 6$ breaths/min, $p<0.01$ ), lower heart rate (98 \pm 19 vs. $108 \pm 22$, beats/min), higher $\mathrm{pH}(7.29 \pm 0.05$ vs. $7.26 \pm 0.06, p<0.01$, higher $\mathrm{PaO}_{2} / \mathrm{FiO}_{2}(228 \pm 70$ vs. $208 \pm 90 \mathrm{mmHg}, p=0.05)$, and higher Glasgow coma scale $(14.8 \pm 0.7$ vs. $14.4 \pm 1.5, p=0.02)$ at the beginning of NIV.

Five $(6 \%)$ patients in the ward were transferred to the ICU for intensive care ( 3 for continuous use of NIV and 2 for intubation) due to progressive deterioration (Table 2). Of the 5 patients, only one died in hospital. The rate of NIV failure, hospital mortality, and the length of stay in hospital did not differ between the two groups. The duration of NIV was longer in the patients who initiated NIV in the ward than those in the ICU (6.1, IQR: 3.0-9.1 vs. 4.0, 2.1-6.6 days, $p<0.01$ ). But, their hospital cost was much lower (3093, IQR: 2214-4352 vs. 4638, 3259-7712 \$USD, $p<0.01$ ). Also, the vital signs from initiation to $24 \mathrm{~h}$ of NIV improved faster among the patients in the ICU than those in the ward (Figure 1).

After propensity matching, 42 patients were left in each group (Table 3 ). The baseline data were comparable between the two groups. The rate of NIV failure and hospital 
TABLE 1: Clinical characteristics of the patients who used NIV in the ward versus those in the ICU.

\begin{tabular}{|c|c|c|c|}
\hline & In the ward $N=83$ & In the ICU $N=319$ & $p$ \\
\hline Age, years & $71 \pm 8$ & $73 \pm 9$ & 0.10 \\
\hline Male/female & $63 / 20$ & $243 / 76$ & $>0.99$ \\
\hline \multicolumn{4}{|l|}{ Underlying disease } \\
\hline Hypotension & $27(33 \%)$ & $110(35 \%)$ & 0.80 \\
\hline Diabetes mellitus & $16(19 \%)$ & $61(19 \%)$ & $>0.99$ \\
\hline Chronic heart disease & $13(16 \%)$ & $63(20 \%)$ & 0.44 \\
\hline Chronic kidney disease & $0(0 \%)$ & $14(4 \%)$ & 0.08 \\
\hline Chronic liver disease & $1(1 \%)$ & $10(3 \%)$ & 0.47 \\
\hline \multicolumn{4}{|l|}{ Data collected at initiation of NIV } \\
\hline APACHE II score & $15 \pm 2$ & $16 \pm 4$ & 0.09 \\
\hline GCS & $14.8 \pm 0.7$ & $14.4 \pm 1.5$ & 0.02 \\
\hline Respiratory rate, breaths/min & $24 \pm 3$ & $28 \pm 6$ & $<0.01$ \\
\hline Heart rate, beats/min & $98 \pm 19$ & $108 \pm 22$ & $<0.01$ \\
\hline Mean arterial pressure, $\mathrm{mmHg}$ & $91 \pm 11$ & $100 \pm 18$ & $<0.01$ \\
\hline $\mathrm{pH}$ & $7.29 \pm 0.05$ & $7.26 \pm 0.06$ & $<0.01$ \\
\hline $\mathrm{PaCO}_{2}, \mathrm{mmHg}$ & $80 \pm 13$ & $83 \pm 17$ & 0.08 \\
\hline $\mathrm{PaO}_{2} / \mathrm{FiO}_{2}, \mathrm{mmHg}$ & $228 \pm 70$ & $208 \pm 90$ & 0.05 \\
\hline
\end{tabular}

NIV = noninvasive ventilation, ICU = intensive care unit, GCS = Glasgow coma scale, APACHE II = acute physiology and chronic health evaluation II.

TABLE 2: Outcomes in patients who used NIV in the ward versus those in the ICU.

\begin{tabular}{|c|c|c|c|}
\hline & In the ward $N=83$ & In the ICU $N=319$ & $p$ \\
\hline NIV failure & $4(5 \%)$ & $35(11 \%)$ & 0.10 \\
\hline Hospital mortality & $3(4 \%)$ & $31(10 \%)$ & 0.08 \\
\hline Transfer to the ICU & $5(6 \%)$ & - & - \\
\hline Duration of NIV, days & $6.1(3.0-9.1)$ & $4.0(2.1-6.6)$ & $<0.01$ \\
\hline The length of stay in hospital, days & $10.2(8.0-15.0)$ & $10.2(6.7-15.0)$ & 0.40 \\
\hline Hospital cost, $\$$ & $3093(2214-4352)$ & $4638(3259-7712)$ & $<0.01$ \\
\hline
\end{tabular}

$\mathrm{NIV}=$ noninvasive ventilation, $\mathrm{ICU}=$ intensive care unit.

mortality did not differ between the two groups (Table 4). Similar with the overall cohort, we also found that the duration of NIV was longer and hospital cost was lower in patients who initiated the NIV in the ward than those in the ICU. Also, the respiratory rate, heart rate, $\mathrm{pH}, \mathrm{PaCO}_{2}$, and $\mathrm{PaO}_{2} / \mathrm{FiO}_{2}$ improved faster within the first $24 \mathrm{~h}$ of NIV in patients who initiated NIV in the ICU than those in the ward (Figure 2). In addition, there was another new finding that the length of stay in hospital was shorter among the patients in the ICU than those in the ward (median 8.8 vs. 10.9 day, $p=0.04)$.

\section{Discussion}

To our knowledge, this is the first head-to-head comparison of treatment failure and costs among COPD patients who used NIV in the ward versus in the ICU. Slower improvement of vital signs and arterial blood gas tests, longer duration of NIV, but lower cost were observed in patients who used NIV in the ward than those in the ICU. Also, the rate of NIV failure and hospital mortality did not differ between the two groups.

A landmark paper published at 2000 has reported that the early use of NIV in the ward among patients with COPD exacerbation reduced the need for intubation and hospital mortality compared with standard care [6]. This study only demonstrated that the use of NIV in the ward was feasible.
During the following 20 years, many studies also showed the benefits of NIV in the ward among COPD population $[17,22,23]$. However, these studies only demonstrated that patients with COPD exacerbation benefited from NIV in the ward but failed to demonstrate the optimal location where the NIV should be used. To our knowledge, our study is the first one head-to-head comparison on the use of NIV in the ward against those in the ICU. It provides a reference for clinical staffs how to select the location to use NIV.

We found an interesting result that patients who used NIV in the ward had a less severe respiratory acidosis and lower cost but a longer duration of NIV compared with those in the ICU. The potential reasons were as follows. First, the physicians and nurses in the ICU were much more than those in the ward when they managed the same number of patients. Second, the ICU physicians and nurses have managed much more NIV patients than those who managed NIV in the ward. So, the experience on NIV management was much richer in ICU physicians and nurses. Third, the two reasons lead to a faster improvement in vital signs and arterial blood gas tests in the ICU patients. Therefore, these reasons can be explained this interesting result.

Delayed admission to the ICU may be associated with increased mortality. A previous study reported by Valentini et al. showed that the mortality was $18 \%$ in patients who directly transferred from the emergency department to respiratory ICU, but it increased to $64 \%$ in cases who 


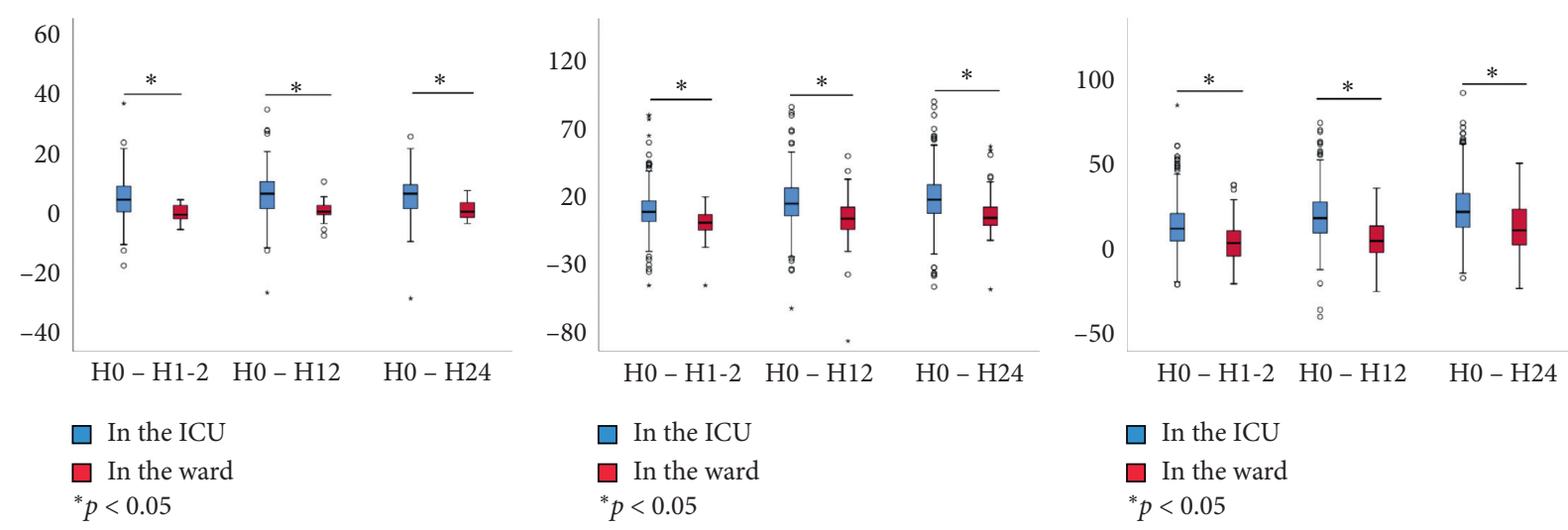

(a)

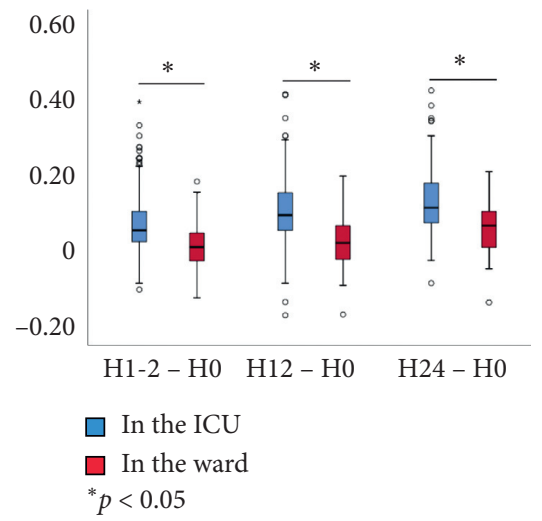

(d) (b)

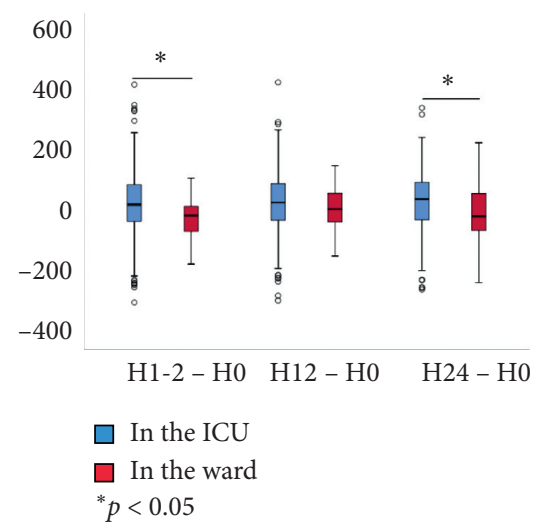

(e)

FIGURE 1: The changes of vital signs and arterial blood gas tests within $24 \mathrm{~h}$ of NIV in overall cohort. (a) $\Delta$ Respiratory rate, breaths/min. (b) $\Delta$ Heart rate, beats/min. (c) $\Delta \mathrm{PaCO}_{2}, \mathrm{mmHg}$. (d) $\Delta \mathrm{pH}$. (e) $\Delta \mathrm{PaO}_{2} / \mathrm{FiO}_{2}, \mathrm{mmHg}$.

TABLE 3: Clinical characteristics in the propensity-matched cohort.

\begin{tabular}{|c|c|c|c|}
\hline & In the ward $N=42$ & In the ICU $N=42$ & $p$ \\
\hline Age, years & $72 \pm 8$ & $72 \pm 9$ & 0.88 \\
\hline Male/female & $32 / 10$ & $33 / 9$ & $>0.99$ \\
\hline \multicolumn{4}{|l|}{ Underlying disease } \\
\hline Hypotension & $16(38 \%)$ & $12(29 \%)$ & 0.48 \\
\hline Diabetes mellitus & $10(24 \%)$ & $11(26 \%)$ & $>0.99$ \\
\hline Chronic heart disease & $6(14 \%)$ & $9(21 \%)$ & 0.57 \\
\hline Chronic kidney disease & $0(0 \%)$ & $1(2 \%)$ & $>0.99$ \\
\hline Chronic liver disease & $0(0 \%)$ & $1(2 \%)$ & $>0.99$ \\
\hline \multicolumn{4}{|l|}{ Data collected at initiation of NIV } \\
\hline APACHE II score & $15 \pm 3$ & $15 \pm 4$ & 0.58 \\
\hline GCS & $14.7 \pm 0.9$ & $14.5 \pm 0.8$ & 0.31 \\
\hline Respiratory rate, breaths/min & $25 \pm 3$ & $26 \pm 8$ & 0.49 \\
\hline Heart rate, beats/min & $104 \pm 20$ & $106 \pm 19$ & 0.31 \\
\hline Mean arterial pressure, $\mathrm{mmHg}$ & $93 \pm 12$ & $95 \pm 15$ & 0.47 \\
\hline $\mathrm{pH}$ & $7.29 \pm 0.04$ & $7.29 \pm 0.05$ & 0.69 \\
\hline $\mathrm{PaCO}_{2}, \mathrm{mmHg}$ & $77 \pm 11$ & $76 \pm 16$ & 0.82 \\
\hline $\mathrm{PaO}_{2} / \mathrm{FiO}_{2}, \mathrm{mmHg}$ & $208 \pm 71$ & $214 \pm 92$ & 0.73 \\
\hline
\end{tabular}

NIV = noninvasive ventilation, ICU = intensive care unit, GCS = Glasgow coma scale, APACHE II = acute physiology and chronic health evaluation II .

transferred from the respiratory ward [24]. This study enrolled all the patients who used NIV in the ICU due to various reasons. However, we only enrolled patients who used the NIV due to COPD exacerbation, and only 5 (6\%) patients in the ward were transferred to ICU due to progressive deteriorations. Among the 5 cases, only one died in hospital. Therefore, the need to transfer to the ICU for escalation therapy is low among COPD patients who used NIV in the ward. Also, the mortality is not high among those who transferred to the ICU. We believe the use of NIV in the ward among COPD patients is an alternative place. 
TABLE 4: Outcomes in the propensity-matched cohort.

\begin{tabular}{|c|c|c|c|}
\hline & In the ward $N=42$ & In the ICU $N=42$ & $p$ \\
\hline NIV failure & $1(2 \%)$ & $4(9 \%)$ & 0.36 \\
\hline Hospital mortality & $2(5 \%)$ & $2(5 \%)$ & $>0.99$ \\
\hline Transfer to the ICU & $2(5 \%)$ & - & - \\
\hline Duration of NIV, days & $7.1(4.1-10.6)$ & $4.2(1.8-5.7)$ & $<0.01$ \\
\hline The length of stay in hospital, days & $10.9(8.6-16.1)$ & $8.8(6.4-15.6)$ & 0.04 \\
\hline Hospital cost, \$ & $3105(2286-4443)$ & $3853(2281-8049)$ & 0.02 \\
\hline
\end{tabular}

NIV=noninvasive ventilation, ICU=intensive care unit.

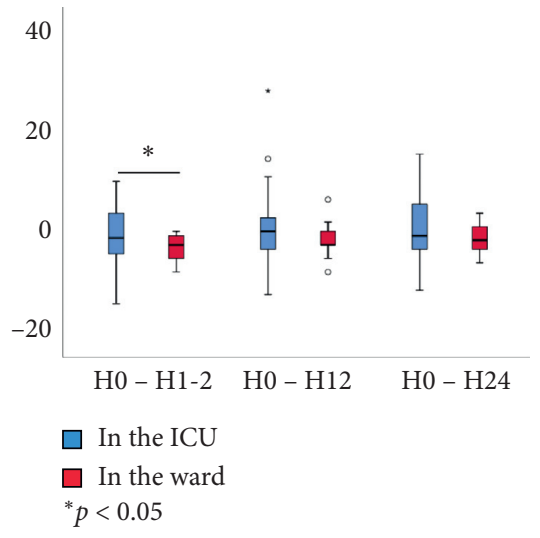

(a)

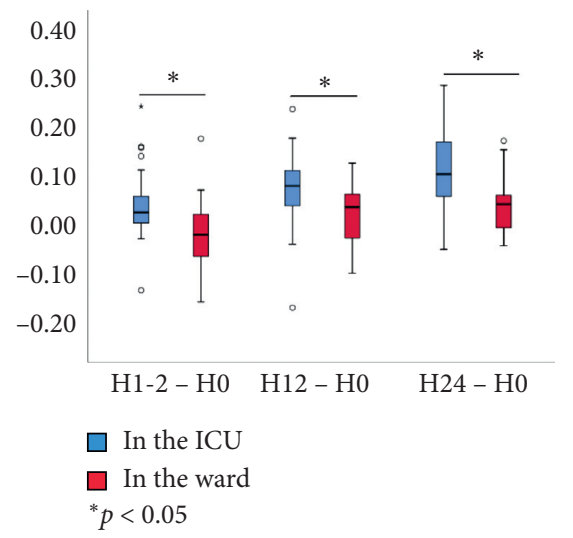

(d)

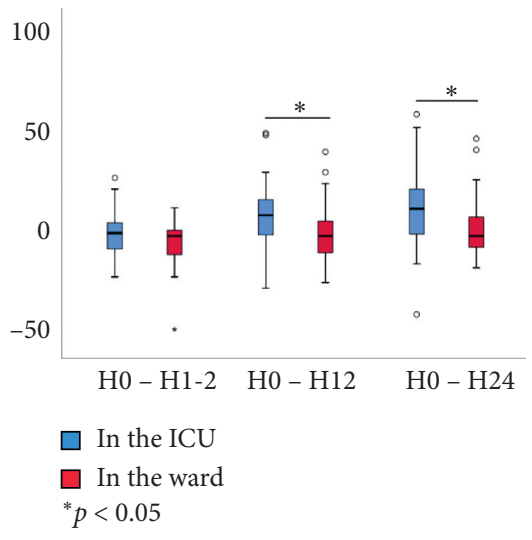

(b)

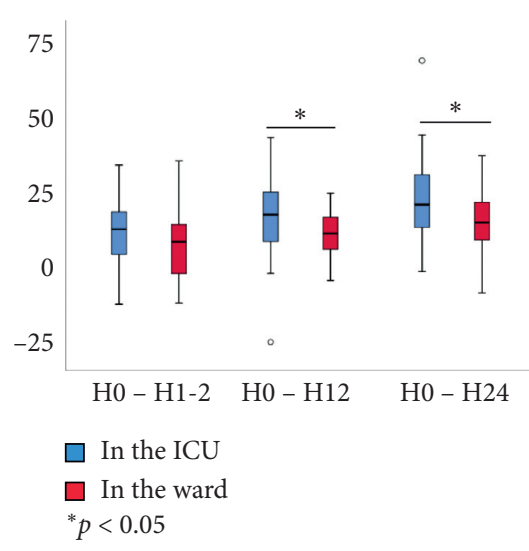

(c)

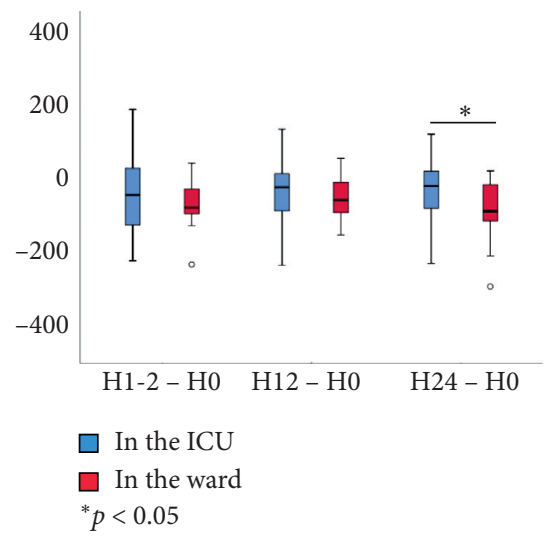

(e)

FIGURE 2: The changes of vital signs and arterial blood gas tests within $24 \mathrm{~h}$ of NIV in propensity-matched cohort. (a) $\Delta$ Respiratory rate, breaths/min. (b) $\Delta$ Heart rate, beats/min. (c). $\Delta \mathrm{PaCO}_{2}, \mathrm{mmHg}$. (d) $\Delta \mathrm{pH}$. (e) $\Delta \mathrm{PaO}_{2} / \mathrm{FiO}_{2}, \mathrm{mmHg}$.

Our study may be limited by the retrospective design. Where to use the NIV was decided by the attending physicians. More serious illness patients were more likely to transfer to the ICU, which lead to unbalanced baseline data between patients in the ICU and those in the ward. However, we performed a propensity-matched analysis to balance the confounders. After propensity matching, the baseline data were comparable. This improves the comparability between the two groups. In addition, the transportation of the patients from the ward to ICU for escalation therapy was also decided by the attending physicians if the respiratory failure progressively deteriorated. Delayed admission to the ICU for escalation therapy may be occurred because the personnel allocation was much lower in the ward than that in the ICU.
Therefore, more attention should be paid to the patients who used the NIV in the ward.

\section{Conclusions}

The use of NIV in the ward is cost effective for COPD patients. The rate of transportation to the ICU for escalation therapy is low. NIV failure rate and mortality did not differ between patients who initiated NIV in the ward and those in the ICU.

\section{Abbreviations}

COPD: Chronic obstructive pulmonary disease

NIV: $\quad$ Noninvasive ventilation 
GCS: $\quad$ Glasgow coma scale

APACHE Acute physiology and chronic health

II: evaluation II

IQR: Interquartile range

ICU: Intensive care unit

\section{Data Availability}

The datasets analyzed during this study are available from the corresponding author upon reasonable request.

\section{Conflicts of Interest}

The authors declare that they have no conflicts of interest in this study.

\section{Authors' Contributions}

Jun Duan and Chuanbo Liu conceived the study, contributed to study design, study management, data acquisition, data interpretation, and manuscript preparation, and took responsibility for the integrity of the whole study. Yueling Hong contributed to study design, data acquisition, data interpretation, and data analysis and drafted the manuscript. Linfu Bai, Lei Jiang, Xiaoli Han, Shicong Huang, and Wenhui $\mathrm{Hu}$ contributed to data acquisition, data analysis, data interpretation, and manuscript revision. All of the authors read and approved the final version.

\section{Acknowledgments}

This study was supported by Chongqing Health Commission (2020FYYX138).

\section{References}

[1] C. Wang, J. Xu, L. Yang et al., "Prevalence and risk factors of chronic obstructive pulmonary disease in China (the China Pulmonary Health [CPH] study): a national cross-sectional study," The Lancet, vol. 391, no. 10131, pp. 1706-1717, 2018.

[2] T. Vos, C. Allen, M. Arora et al., "Global, regional, and national incidence, prevalence, and years lived with disability for 310 diseases and injuries, 1990-2015: a systematic analysis for the Global Burden of Disease Study 2015," Lancet, vol. 388, pp. 1545-1602, 2016.

[3] M. Zhou, H. Wang, J. Zhu et al., "Cause-specific mortality for 240 causes in China during 1990-2013: a systematic subnational analysis for the Global Burden of Disease Study 2013," The Lancet, vol. 387, no. 10015, pp. 251-272, 2016.

[4] W. Chen, J. M. FitzGerald, D. D. Sin et al., "Excess economic burden of comorbidities in COPD: a 15-year populationbased study," European Respiratory Journal, vol. 50, 2017.

[5] L. Appendini, A. Patessio, S. Zanaboni et al., "Physiologic effects of positive end-expiratory pressure and mask pressure support during exacerbations of chronic obstructive pulmonary disease," American Journal of Respiratory and Critical Care Medicine, vol. 149, no. 5, pp. 1069-1076, 1994.

[6] P. Plant, J. Owen, and M. Elliott, "Early use of non-invasive ventilation for acute exacerbations of chronic obstructive pulmonary disease on general respiratory wards: a multicentre randomised controlled trial," The Lancet, vol. 355, no. 9219, pp. 1931-1935, 2000.
[7] Collaborative Research Group of Noninvasive Mechanical Ventilation for Chronic Obstructive Pulmonary Disease, "Early use of non-invasive positive pressure ventilation for acute exacerbations of chronic obstructive pulmonary disease: a multicentre randomized controlled trial," Chinese Medical Journal, vol. 118, pp. 2034-2040, 2005.

[8] J. A. Wedzicha, M. Miravitlles, J. R. Hurst et al., "Management of COPD exacerbations: a European respiratory society/ American thoracic society guideline," European Respiratory Journal, vol. 49, 2017.

[9] A. C. Davidson, S. Banham, M. Elliott et al., "BTS/ICS guideline for the ventilatory management of acute hypercapnic respiratory failure in adults," Thorax, vol. 71, no. 2, pp. ii1-35, 2016.

[10] S. P. Keenan, T. Sinuff, K. E. A. Burns et al., "Clinical practice guidelines for the use of noninvasive positive-pressure ventilation and noninvasive continuous positive airway pressure in the acute care setting," Canadian Medical Association Journal, vol. 183, no. 3, pp. E195-E214, 2011.

[11] M. S. Stefan, M.-S. Shieh, P. S. Pekow, N. Hill, M. B. Rothberg, and P. K. Lindenauer, "Trends in mechanical ventilation among patients hospitalized with acute exacerbations of COPD in the United States, 2001 to 2011," Chest, vol. 147, no. 4, pp. 959-968, 2015.

[12] L. C. Myers, M. K. Faridi, P. Currier, and C. A. Camargo, "ICU utilization for patients with acute exacerbation of chronic obstructive pulmonary disease receiving noninvasive ventilation," Critical Care Medicine, vol. 47, no. 5, pp. 677-684, 2019.

[13] J. Phua, K. Kong, K. H. Lee, L. Shen, and T. K. Lim, "Noninvasive ventilation in hypercapnic acute respiratory failure due to chronic obstructive pulmonary disease vs. other conditions: effectiveness and predictors of failure," Intensive Care Medicine, vol. 31, no. 4, pp. 533-539, 2005.

[14] D. Contou, C. Fragnoli, A. Cordoba-Izquierdo, F. Boissier, C. Brun-Buisson, and A. W. Thille, "Noninvasive ventilation for acute hypercapnic respiratory failure: intubation rate in an experienced unit," Respiratory Care, vol. 58, no. 12, pp. 2045-2052, 2013.

[15] S. P. Trethewey, R. G. Edgar, A. M. Turner et al., "Ward-based non-invasive ventilation in acute exacerbations of COPD: a narrative review of current practice and outcomes in the UK," Healthcare (Basel), vol. 6, 2018.

[16] L. Cabrini, M. Antonelli, G. Savoia, and M Landriscina, "Noninvasive ventilation outside of the intensive care unit: an Italian survey," Minerva Anestesiologica, vol. 77, no. 3, pp. 313-322, 2011.

[17] S. Fiorino, L. Bacchi-Reggiani, E. Detotto et al., "Efficacy of non-invasive mechanical ventilation in the general ward in patients with chronic obstructive pulmonary disease admitted for hypercapnic acute respiratory failure and $\mathrm{pH}$," Internal Medicine Journal, vol. 45, no. 5, pp. 527-537, 2015.

[18] W. Chen and Z. Qing-yuan, "Guideline for mechanical ventilation in patients with acute exacerbation of chronic obstructive pulmonary disease (2007)," Zhongguo Wei Zhong Bing Ji Jiu Yi Xue, vol. 19, pp. 513-518, 2007.

[19] L. Fan, Q. Zhao, Y. Liu, L. Zhou, and J. Duan, "Semiquantitative cough strength score and associated outcomes in noninvasive positive pressure ventilation patients with acute exacerbation of chronic obstructive pulmonary disease," Respiratory Medicine, vol. 108, no. 12, pp. 1801-1807, 2014.

[20] J. Duan, S. Wang, P. Liu et al., "Early prediction of noninvasive ventilation failure in COPD patients: derivation, internal 
validation, and external validation of a simple risk score," Ann Intensive Care, vol. 9, p. 108, 2019.

[21] J. Duan, X. Tang, S. Huang, J. Jia, and S. Guo, "Protocoldirected versus physician-directed weaning from noninvasive ventilation," The Journal of Trauma and Acute Care Surgery, vol. 72, no. 5, pp. 1271-1275, 2012.

[22] K. M. McLaughlin, I. M. Murray, G. Thain, and G. P. Currie, "Ward-based non-invasive ventilation for hypercapnic exacerbations of COPD: a "real-life" perspective," QJM, vol. 103, no. 7, pp. 505-510, 2010.

[23] M. Yalcinsoy, C. Salturk, S. Oztas et al., "Can patients with moderate to severe acute respiratory failure from COPD be treated safely with noninvasive mechanical ventilation on the ward?" International Journal of Chronic Obstructive Pulmonary Disease, vol. 11, pp. 1151-1160, 2016.

[24] I. Valentini, A. M. G. Pacilli, P. Carbonara et al., "Influence of the admission pattern on the outcome of patients admitted to a respiratory intensive care unit: does a step-down admission differ from a step-up one?" Respiratory Care, vol. 58, no. 12, pp. 2053-2060, 2013. 